\title{
Fronteras, arquitectura y consumo: hacia una heterotopía de la ciudad ${ }^{2}$
}

\author{
Borders, architecture and consumption: \\ towards a heterotopy of the city
}

\section{Resumen}

Este artículo intenta hacer una reflexión desde los estudios fronterizos de la ciudad y el espacio, donde el consumo y el uso urbano son acaparados constantemente por el capital. Sin embargo, la ciudad crea dentro de sí fronteras en las que se elaboran y se retransmiten deseos y conjeturas, y allí todo puede ser posible. En esta heterotopía, como lo llamaría Foucault, se reconstruyen las ciudades cotidianamente, ese espacio donde muchas veces la arquitectura pasa a ser consumo visible en la urbe.

Palabras clave: fronteras, ciudad, arquitectura, consumo, espacio, heterotopía.

\begin{abstract}
This article reflects on border studies of the city and its space, where every day the consumption and the urban use is monopolized by the capital. Nevertheless, the city creates inside itself places where desires and guessing works are elaborated and re-transmitted, and where everything can be possible. It is in this "heterotopia", as Foucault would call it, which the cities are reconstructed every day; it is in this space where the architecture becomes a visible consumption at the metropolis.
\end{abstract}

Keywords: borders, city, architecture, consumption, space, heterotopy.

1 Historiador y sociólogo. Candidato a Doctor en Historia y Civilización de la Escuela de Altos Estudios en Ciencias Sociales, París. Correo electrónico: causeche@gmail.com

2 Artículo de reflexión derivado de la tesis doctoral Les élites et l'exclusion de l'autre. Construction identitaire et imaginaires nationaux en Colombie (1880-1922). 


\section{Introducción}

Perec (2000) describía en su ya célebre obra Espéces d'espaces algunos elementos que pueden llegar a componer el espacio en que vivimos: la habitación, la cama, la calle, un inmueble, el barrio, la ciudad, etc.; pero al mismo tiempo era claro al descifrar que, al final, el espacio no termina siendo sino aquello que logramos ver, aquello que está limitado por nuestra mirada: lo alto, lo bajo, la izquierda, la derecha, un adelante, un atrás, un cerca, un lejos. Para el ser humano, por tanto, el espacio cotidiano, en esas circunstancias, termina siendo estrecho, delimitado. ¿Qué son, entonces, estos elementos que componen nuestro espacio real, sino fronteras donde se construye la cotidianidad, sino líneas que demarcan nuestro tránsito, nuestro día a día?

Para algunos investigadores, estas fronteras muchas veces invisibles, sea una calle, un muro o sea nuestra propio lugar de habitación, construyen un "adentro" y un "afuera" que termina de elaborar eso que Lefebvre (2000) ha denominado "arquitectónica espacial", donde confluyen la naturaleza y lo social (p. 213), en un juego que va más allá de lo visible. Sin embargo, hace mucho se ha empezado a pensar el espacio como algo más allá de esa "dualidad" que tan comúnmente se asocia a la epistémica fronteriza. Ese "adentro-afuera" pasa a ser parte, también, de una serie de eslabones espaciales que traspasan una idea muchas veces plana del espacio y presenta múltiples formas; un espacio que genera enclaves, lugares, líneas que fluyen constantemente creando múltiples fronteras, múltiples pliegues y, al mismo tiempo, creando la vida cotidiana. Este sistema vivo se repliega sobre sí mismo; su ideal, como lo ha demostrado Sloterdijk (2002), es una esfera o una burbuja, y allí se vuelve ese universo esferático, anegado de pliegues, de fronteras donde el ser humano nace, sobrevive e interactúa (Debray, 2010).

La ciudad, por tanto, es sin duda el escenario fundamental en el que hoy en día transcurre la cotidianidad humana. Y en ese sentido, preguntarnos por el destino de lo urbano equivale a tra- tar de prever las condiciones de posibilidad del sujeto en un planeta que cada día olvida más el campo y en el que toda su productividad mental la encamina hacia la ciudad. Se hace necesario, entonces, hablar de la ciudad-espacio o de la ciudad-mundo, y hacer posible que dentro de ella se redireccionen los alcances y componentes de un nuevo contrato entre la naturaleza, el gobierno, el mercado y la sociedad, en el que se establezcan proyectos concertados de ciudadanía orientados no solo a la preservación de la especie, sino, y sobre todo, a la obtención de ese viejo y hasta ahora utópico ideal que resulta ser la justicia social (Herrera, 2002; Klotz, 2006)

En esta medida, y dentro del marco que en la actualidad brinda la globalización económica y cultural, el presente artículo se orienta a establecer el papel de la relación de consumo y ciudad, desde lo concerniente al dimensionamiento de una particular idea del urbanitas, un habitante del mundo comprometido con ella, de cara a esas nuevas apariciones arquitectónicas que, desde la percepción de una nueva "reelaboración de la ciudad", se levantan como una nueva técnica de consumo dentro de invisibles fronteras urbanas que desbarajustan el tejido social cotidiano.

Para ese efecto, el estudio del espacio - que es donde transcurre el mundo urbano y donde se difumina la ciudad- es fundamental para la construcción de ese nuevo "atlas" por donde circulan los intercambios y donde ahora, como lo señala Serres (1995), "se abrevia el tránsito entre lo cercano y lo lejano cuyo cuerpo cruzado o disuelto encana los extremos opuestos de las diferencias o las transiciones similares de las identidades" ( $p$. 31). El consumo fluye libremente entre las fronteras de la urbe y se instala, de manera invisible, en el centro de la vida cotidiana, atravesada por el caminante. Así, la forma urbana, además de manifestarse de manera fronteriza, en sus demarcaciones entre un "acá" y un "allá”, en líneas por donde se transita, se manifiesta también, como lo dice Virilio (1993), en la "programación de un empleo del tiempo" (p. 15). Y es allí en donde la arquitectura, las moles de cemento, vidrio, ma- 
dera, etc., funcionan como enclaves fronterizos espaciales que rompen con el uso cotidiano del tiempo del transeúnte.

\section{Hacia una heterotopía de la ciudad y la frontera}

Desde finales del siglo XVIII, nos dice Foucault (1980), el problema del espacio empieza a ser visto como un problema histórico-político, y no como un tratamiento geográfico-físico donde se desarrollaba la expansión de un pueblo, de una cultura, como un simple lugar de residencia. De este modo, la arquitectura (como primer elemento del espacio histórico-político) en ese momento comienza a estar ligada con los problemas de la población, de la salud, del urbanismo; variables sociales que van a estar estrechamente ligadas a la manera de servirse de la organización del espacio para fines económicos-políticos.

Existen unos lugares reales, unos lugares efectivos, que están diseñados en la institución misma de la sociedad. Foucault (1984) dice que estos son especies de contraemplazamientos, ciertas utopías que son creadas probablemente en toda cultura, en toda civilización. Allí, los emplazamientos reales que se pueden encontrar en el interior de una cultura están a la vez representados como especies de lugares que están fuera de todos los lugares, como una especie de Aleph borgiano, pero que son, sin embargo, efectivamente localizables: estas son las heterotopias (Foucault, 1984). Estos espacios creados por la cultura, donde pasa todo y no pasa nada, donde confluye la muerte y la vida, el miedo y la locura, definen el espacio urbano como ciudad; una heterotopía donde el mundanal gentío se entrecruza y donde se ejercen múltiples poderes sobre los poderes, múltiples fronteras sobre las fronteras; una heterotopia donde el deseo no está ausente.

En esta especie de Non-lieux, como los ha denominado Augé (1992) y que pertenecen a la experiencia de los espacios de vida, e cristaliza la existencia individual: el lugar de trabajo, los luga- res de placer y de ocio, el paseo, el encuentro, la vida misma que no pertenece al territorio sino al lugar en el espacio.

La ciudad emerge, por tanto, como un escenario espacial, uno donde confluyen múltiples poderes y donde se desarrolla un proyecto de globalización económico y cultural acelerado, una economía de mercado que tiene al consumo como referente primero y fundamental. La ciudad plena de movimientos y de múltiples encuentros es un espacio rizomático en el que habitan múltiples submundos en uno solo y donde el "afuera" carece de imagen, de significación, de subjetividad (Deleuze y Guattari, 2005).

En estos distintos pliegues, que se elaboran de manera fronteriza, se forma ese espacio urbano que elabora la "esfera" de la vida (Sloterdijk, 2010), esa heterotopía en la que las fronteras trazadas son testigo del pasado y, al mismo tiempo, actores vivos, "lugares de memoria y algunas veces de resentimiento" (Foucher, 2007). Tanto la ciudad ausente como la ciudad deseo son atravesadas por medio del consumo en medio de múltiples líneas de fuga que carecen de fin. Bachelard, nos dice Foucault, nos ha enseñado que no vivimos en un espacio homogéneo y vacío; por el contrario, habitamos en un espacio cargado de cualidades, un espacio que quizás también esté visitado por fantasmas:

Es un espacio liviano, etéreo, transparente, o bien un espacio oscuro, rocalloso, obstruido: es un espacio de arriba, es un espacio de las cimas, o es por el contrario un espacio de abajo, un espacio de barro, es un espacio que puede estar corriendo como el agua viva, es un espacio que puede estar fijo, detenido como la piedra o como el cristal (Foucault, 1984).

La ciudad contemporánea se constituye en el escenario de nuevos procesos económicos y culturales a partir de la presencia de una diversidad de espacios públicos, expresión de una multiplicidad de estilos de vida en que la mirada es la gran vía de canalización de los deseos que incansablemente generan los productos. 
De esta manera, detrás de la configuración espacial existen unos componentes de transformación urbana en el panorama de la ciudad posindustrial que se derivan de los nuevos modelos económicos, del incremento de movilidad y, principalmente, del desarrollo y la implementación de sistemas de redes, que hoy obligan a la definición de nuevas formas de organización territorial. En este margen se encuadra el consumo en términos conceptuales, y se incluyen, además del deseo, nuevos hábitos asociados al incremento del tiempo libre y la demanda de diferentes formas de ocio y cultura. Allí pueden definirse aspectos innovadores en cuanto a las tipologías urbanas y articulaciones territoriales y diferentes espacialidades fronterizas. Al mismo tiempo, en este territorio "transgresor" (Foucault, 2004) - o como diría Bataille: la experiencia pura y más desnuda del afuera-nacen nuevas experiencias del cuerpo, del espacio, donde el otro nunca es invisible; y también se crean redes, muchas veces ilusorias, en las que el consumo pasa a ser apropiación, apropiación del deseo.

Estas redes que se crean en estos espacios heterogéneos son elaboradas en lo que Foucault (1984) entendería como una especie de vacio dentro del cual localizamos individuos, cosas; una red de relaciones que delinean lugares irreductibles unos a otros y absolutamente imposibles de superponer. La mayor parte de estos lugares que se insertan dentro lo espacial-urbano son dominados por la masa, que se encarga de finiquitar el proceso de explotación de la mirada y el deseo, el consumo.

\section{Arquitectura y consumo}

Un caso interesante y particular como materia de análisis dentro de la construcción de "redes de consumo urbana" puede ser la arquitectura, no como lugar, como espacio, como elemento claramente fronterizo. En este sentido, como nos dice Benjamin (2003), la masa es una matriz de la que actualmente surte, como vuelto a nacer, todo comportamiento frente a las obras artísticas. La cantidad se ha convertido en calidad: el crecimiento masivo del número de participantes ha modifica- do la índole de su participación. Así, "el individuo está sometido a la tentación de hurtarse a dichas tareas, el arte abordará la más difícil e importante movilizando a las masas" (Benjamin, 2003).

La arquitectura nace en el momento en que se empiezan a trazar las primeras ciudades; por lo tanto, una historia de la arquitectura es una historia de la ciudad: "La arquitectura es así, connatural a la formación de la civilización y un hecho permanente, universal y necesario" (Rossi, 1999). De esta manera, la configuración de las ciudades se ha visto igualmente modificada en tanto se ha acrecentado el consumo de la arquitectura. Su carácter supera lo visual doblemente; el consumo es doble, el deseo es múltiple y, por tanto, ya no solo se va por la obra de arte en sí, sino que también se elige el lugar donde se quiere ver la obra de arte en producción. El edificio, la plaza, el centro comercial se convierten, tanto por su arquitectura como por lo que representan, en los lugares en los que se emplaza, en una heterotopía, en múltiples fronteras donde chocan el consumo y la visión irreal del arte para el arte. Ya no es la historia del arte, es la historia de la construcción, de la arquitectura, la que roza la maraña urbana; se elabora así una historia que transgrede el trazo territorial o urbanístico con el único fin del consumo.

El uso y la contemplación, como nos dice Benjamin (2003), constituyen la edificación, lo táctil y lo óptico; en suma, la estética frente a la distribución del espacio físico. Y allí se entretejen ciertos tipos de relaciones que la población, en forma espontánea, establece con la construcción espacial y que, al mismo tiempo, está signado por las características culturales que han logrado consolidarse hasta configurar una identidad. Este carácter cultural contiene una tendencia naturalmente lúdico-recreativa que la cotidianidad impulsa en la ciudad. Desde esta perspectiva, la arquitectura, en su dimensión lúdica, recrea un tipo de relaciones que se establecen entre el devenir ciudadano de la población, sus diversos quehaceres y el espacio que los alberga y que los relaciona. Lo verdaderamente lúdico es la capacidad del ciudadano de apropiarse y transformar el espacio (Herrera, 2002). 
Esta idea de configurar zonas exclusivas, donde la arquitectura estructura un urbanismo que permite el disfrute lúdico de la morfología ciudadana, producto de la idea capitalista de acaparar el espacio citadino, ha llegado incluso a avizorar la posibilidad de una "civilización urbana". De esta manera, cualquier práctica de consumo puede llegar a considerarse en sí un acto cultural, si lo entendemos como un conjunto de procesos de apropiación y usos de productos en los que el valor simbólico prevalece sobre los valores de uso y de cambio, o donde al menos estos últimos se consideran subordinados a la dimensión simbólica (García-Canclini, 2002).

Dentro la construcción de la especialidad urbana, en cuanto configuración y conformación de líneas espaciales fronterizas, como también dentro de las relaciones que se establecen como fundamento de la heterotopía a la que pertenece, existe un fundamento histórico y artístico que se instala en el terreno de la cultura, en la medida en que es un proceso que indica permanencia, ya que integra pasado, presente y futuro (GarcíaCanclini, 2002). La arquitectura forma parte de esta industria cultural de la que no solo la estética y el arte se hacen partícipes. La reproducción de una estética de construcción, de un nombre arquitectónico como Gaudí, Gehry, Calatrava, Niemeyer o incluso Le Corbusier, cuya verdadera potencialidad recaía en la funcionalidad de la arquitectura, mas no en la estética, deriva ahora en firmas que deambulan incólumes por distintas ciudades. Y ello permite no solo una variación estético-lúdica de la urbe, sino también un cambio en el interior de la productibilidad económica. Así, la multiplicación de edificios y la manera de propagar estas moles en un espacio de sociabilización transforman la manera de pensar y de ver del transeúnte incauto, que sin razón alguna ve cómo su "lugar" deviene consumo.

De esta manera, como nos dice MartínBarbero (1987), en contra de toda estética idea- lista hemos de aceptar que el arte logra su autonomía en un movimiento que lo separa de la ritualización, lo hace mercancía y lo aleja de la vida. Todo queda en un segundo plano: el espacio, el lugar, las relaciones que se tejen, la materialidad o pertinencia de una estructura que sobresale frente a otros diminutos estéticos. La arquitectura en esta heterotopia es consumo, como se ha convertido el cine o la literatura. Esta tendencia, que puede ver sus inicios a finales del siglo XIX y comienzos del XX con la llamada "arquitectura de pabellones", donde se plantearon los nuevos lineamientos tecnológicos y donde se marcaban las tendencias bajo las órdenes de órganos estatales, encontró en estas estructuras una eficaz manera de vender la ciudad.

El Pabellón de Barcelona, por ejemplo, elaborado por Mies Van der Rohe para la exposición Universal de 1929, desmontado meses más tarde, se convirtió en un paradigma en el que lo esencial no era lo que se mostraba dentro; era el pabellón mismo ${ }^{3}$, y un modelo de lo que vendría a llamarse "arquitectura efímera" y más tarde "arquitectura de seducción”. Un ejemplo más reciente es el Museo Guggenheim de Frank Gehry en Bilbao, cuya obra, junto con el puente de Calatrava, le dieron un valor simbólico y de consumo importante al nuevo desarrollo de la ciudad, donde el turista de paso, sin entrar al museo, se lleva el recuerdo plasmado en una foto de la posesión imaginada de una mole arquitectónica.

Estas construcciones empiezan a ocupar, como señala Sennett (1990), los "espacios de autoridad", que antes eran ocupados por catedrales, hospitales, pasajes y otras arquitecturas que aún hoy en día promocionan el consumo de una ciudad. Ciudades como Venecia se han apropiado de la nueva arquitectura, donde prácticamente toda la arquitectura está hecha para el consumo, donde los puentes clásicos comparten con nuevos puentes como el "puente de la constitución" de Calatrava; o también Madrid, donde el Museo

3 En 1980 se pensó la iniciativa de la reconstrucción del pabellón, cuya obra se llevaría a cabo desde 1983 a 1986, fecha de su inauguración. 
Reina Sofía comparte su edificio entre un antiguo hospital y una nueva producción arquitectónica elaborada por Jean Nouvel.

Estas apropiaciones sirven no solamente como la readecuación de los espacios culturales hacia una nueva forma de consumo, sino también como una suplantación de los espacios fronterizos antiguos por nuevas formas espaciales que condicionan la memoria del transeúnte. De esta manera, esa creación de nuevos medios de producción, dominados anteriormente por formas antiguas, que correspondían, como nos dice Benjamin (2000), a una conciencia colectiva de distintas imágenes en donde se entrecruzan lo nuevo y lo viejo y que se ven ahora cristalizadas por el deseo, cuyo objetivo es suprimir los antiguos productos sociales y suplantarlos por una nueva memoria colectiva, a través de nuevos productos que renuevan la misma idea de consumo.

\section{Conclusión}

Nos encontramos quizás ante lo que Virilio (1993) denominó una "degradación de lo urbano”. Allí, el conjunto de elementos de la vida so-

\section{Referencias}

Augé, M. (19992). Non-Lieux. Introduction à une anthropologie de la sur modernité. París : Le Seuil.

Benjamin, W. (2003). La obra de arte en al época de su reproductibilidad técnica. México: Ítaca.

Benjamin, W. (2000). Paris, capitale du XIXe siècle. En W. Benjamin, Ouvres (3.a ed.). París: Gallimard.

Debray, R. (2010). Éloge des frontières. Barcelona : Gallimard. cial en el espacio fronterizo se entremezclan con la degradación ligada a las estructuras económicas y políticas de la ciudad. Por ello es paradójico que la arquitectura, en ese sentido, sirva de impulso a la solución de problemas en ciudades donde el tejido social está desmembrado y donde las fronteras ya no solo demarcan la vida cotidiana, sino también la vida social y económica. Pobres, ricos, todos forman parte del mismo espacio y transitan ahora por esta frontera alrededor de una mole creada para reactivar la imagen y, con ello, el consumo.

Por tanto, los cambios de especialidad de ese lugar "otro", donde se construye la heterotopia urbana, aparecen de la mano cuando el deseo y el consumo ligan al arte y a la cultura para su máxima reproductiva: el capital. La ciudad cambia, se transforma, al mismo tiempo que los deseos aparecen y el mundo urbano se agobia de estas espacialidades variantes que desarman lo estético o lo transforman en una incertidumbre social, llena de lugares, de construcciones y plataformas arquitectónicas que muchas veces no dicen absolutamente nada más allá que lo que su estética refleja, pero que deberían llevar consigo no solo el peso del capital, sino también el peso de la historia.

Deleuze, G. y Guattari, F. (2005). Rizoma. Barcelona: Pre-Textos.

Foucault, M. (1980). El ojo del poder. Entrevista con Michel Foucault. En J. Bentham, El Panóptico. Barcelona: Ediciones de La Piqueta.

Foucault, M. (1967). De los espacios otros.: Architecture, Mouvement, Continuité, 5. Foucher, M. (2007). L'obsession des frontières. París: Perrin.

García Canclini, N. (2002). Las industrias culturales en la crisis del desarrollo de América Latina. Encuentros, 43, 39-56.

Herrera, C. (2002). El capital cultural y su impacto en el desarrollo. Encuentros, 43, 2-20. 
Klotz, M. (2006). Arquitectura para el consumo. $A R Q, 62,54-56$.

Lefebvre, H. (2000). La production de l'espace. París: Anthropos.

Martín-Barbero, J. (1987). De los medios a las mediaciones. Comunicación, cultura y hegemonia. Barcelona: Gustavo Gille.

Perec, G. (2000). Espèces d'espaces. París: Galilée.
Rossi, A. (1999). La arquitectura de la ciudad. Barcelona: Plaza Edición.

Serres, M. (1995). Atlas. Madrid: Cátedra.

Sennet, R. (1990). La conscience de l'ceil. París: Verdier.

Sloterdijk, P. (2010). Bulles. Sphères I. París: Pluriel.

Virilio, P. (1993). L'espace critique. París: Christian Burgois. 